\title{
Application of the enzyme-linked immunosorbent assay (ELISA) in the serodiagnosis of syphilis
}

\author{
J. VELDKAMP AND A. M. VISSER \\ National Institute of Public Health, Bilthoven, The Netherlands
}

The laboratory's role in the diagnosis of syphilis mainly depends upon serological methods. In the Regional Public Health Laboratories there is a need for a simple, inexpensive, specific test, which is sensitive in all stages of syphilis, and in which mechanization of all steps is feasible.

The enzyme-linked immunosorbent assay (ELISA) seemed to be very promising (Engvall and Perlmann, 1971, 1972; Ruitenberg, Ljungström, Steerenberg, and Buys, 1975). With this technique quantitation of specific antibodies is obtained by alkaline phosphataselabelled anti-immunoglobulin in tubes coated with antigen. The enzyme remaining in the tubes after washing provides a measure of the amount of specific antibody in the serum.

In order to ascertain the diagnostic value of each new serological method, it is necessary, above all, to determine its specificity and sensitivity. Therefore the results of the ELISA test were compared with those of other serological tests for syphilis on 'problem' sera referred to our laboratory.

\section{Material and methods}

SERA

A total of 517 problem sera were tested with the $T$. pallidum immobilization (TPI) test, the fluorescent treponemal antibody absorption (FTA-ABS) test, the Reiter protein complement-fixation (RPCF) test, the Venereal Disease Research Laboratory (VDRL) slide test, the Kolmer complement-fixation test, and the ELISA test.

The sera were divided into the following groups:

(1) Primary syphilis, untreated (32)

(2) Primary syphilis, treated (25)

(3) Secondary syphilis, untreated (16)

(4) Secondary syphilis, treated (18)

(5) Latent syphilis, treated and untreated (58)

(6) Congenital syphilis, treated and untreated (10)

(7) Syphilis of the central nervous system, treated and untreated (20)

(8) Cardiovascular syphilis, treated and untreated (8)

(9) Other cases of syphilis, treated and untreated (58)

Received for publication December 16, 1974
(10) Presumed biological false positive reactors (BFP) (42)

(11) Sera of persons in whom the risk of syphilis infection was especially high (220)

(12) Sera of persons with only a weakly reactive FTAABS test $(+)$ with no clinical evidence or history of syphilis (10)

\section{SEROLOGICAL TECHNIQUES}

The VDRL and the Kolmer test were performed according to the procedure recommended in the Manual of Tests for Syphilis (USPHS, 1969), with the modification that the Kolmer test was started with a serum dilution of $1: 1$. The RPCF test was done using $1 \frac{1}{2}$ units of complement and starting with undiluted serum (Bekker, de Bruijn, and Miller, 1966).

The FTA-ABS test was performed according to the procedure recommended in the Manual of Tests for Syphilis, with the following modifications: serum dilution $1: 12$, and using an ultrasonicate of Reiter treponemes for absorption of the sera. Results were recorded as -, + , ,+++++ , and ++++ . The results were reported to the clinician as negative, doubtful (weakly reactive) $(+)$, or positive $(++,+++$, and ++++$)$.

The TPI test was performed with the addition of $100 \mu \mathrm{g}$. lysozyme per $\mathrm{ml}$. to the sustaining medium (Bekker and Onvlee, 1955; Kent and De Weerdt, 1963).

\section{ANTIGEN}

An ultrasonic preparation of a virulent human strain of $T$. pallidum was used as antigen, as described by Miller, de Bruijn, Bekker, and Onvlee (1966). Briefly, treponemes were extracted from infected rabbit testes, with extracting medium, consisting of equal parts of inactivated rabbit serum and 1/7 M saline. The medium with treponemes was centrifuged at $200 \mathrm{G}$. for $10 \mathrm{~min}$. to remove gross tissue particles.

The organisms were then sedimented in the cold at $19,000 \mathrm{G}$. for $90 \mathrm{~min}$., washed three times with $20 \mathrm{ml}$. chilled $0.075 \mathrm{M}$ sodium citrate, and homogenized with needle and syringe. After dilution with $1 / 7 \mathrm{M}$ saline ultrasonic preparations were made from these suspensions (D'Alessandro and Dardanoni, 1953).

\section{ENZYME-CONJUGATED ANTI-IMMUNOGLOBULIN}

Alkaline phosphatase conjugated to sheep anti-human IgG was prepared as described by Engvall and Perlmann 
(1971). A $0.5 \mathrm{mg}$. amount of antibody was conjugated with $1.5 \mathrm{mg}$. enzyme by the addition of glutaraldehyde. The enzyme preparation used was alkaline phosphatase Sigma type VII (Sigma chemical company, St. Louis, Mo, U.S.A.). Conjugates were stored in the cold $\left(+4^{\circ} \mathrm{C}\right.$.).

\section{ELISA}

The antigen, serum, and conjugate dilutions were determined by checkerboard titrations. In our system we used an antigen dilution of $1: 100$, a serum dilution of $1: 100$, and a conjugate dilution of $1: 250$.

Initially, the ELISA was performed as described by Engvall and Perlmann (1972). In short, disposable polystyrene tubes were coated with antigen by incubating the tubes with $1 \mathrm{ml}$. antigen solution in a water bath at $37^{\circ} \mathrm{C}$. for $3 \mathrm{hrs}$. The tubes were stored with the antigen solution in the cold $\left(+4^{\circ} \mathrm{C}\right.$.) until used. Before assay the tubes were washed three times with 0.9 per cent. $\mathrm{NaCl}$ containing 0.05 per cent. Tween 20 .

Sera were diluted $(1: 100)$ with phosphate buffered saline (PBS) containing 0.05 per cent. Tween 20 and 0.02 per cent. $\mathrm{NaN}_{3}$. One ml. of the serum dilution was added to each tube. Tubes were set up on a Thomas rotating apparatus (speed 8) at room temperature for $6 \mathrm{hrs}$. After washing ( 3 times) $1 \mathrm{ml}$. of the conjugate dilution (1:250 in PBS-Tween) was added. Tubes were incubated overnight at room temperature (16 hrs).

Excess conjugate was removed by washing three times. Finally, the amount of enzyme bound to the tubes was determined by adding to each tube $1 \mathrm{ml}$. $1 \mathrm{M}$ diethanol amine buffer (pH 9.8) containing $1 \mathrm{mg} . / \mathrm{ml}$. p-nitrophenyl phosphate (Sigma) and $10^{-3} \mathrm{M} \mathrm{MgCl}_{2}$. The reaction product (p-nitrophenolate) possesses a yellow colour which was measured in a spectrophotometer at $400 \mathrm{~nm}$., after stopping the reaction after a suitable time (1-2 hrs) by addition of $0.1 \mathrm{ml}$. $\mathrm{N} \mathrm{NaOH}$.

The amount of antibody present in the serum was expressed as the extinction value. In each experiment we used three control sera: one strongly positive, one weakly positive, and one negative control serum.

Each serum showing an extinction value equal to or higher than the value obtained with the weakly positive control serum was scored as reactive. Each serum showing an extinction value 1 to 10 per cent. lower than the weakly positive control serum was arbitrarily scored as weakly reactive.

Comparative studies were carried out with regard to the incubation time. Finally the following modifications were introduced:

Incubation time for serum dilution $1 \mathrm{hr}$ in a waterbath at $37^{\circ} \mathrm{C}$. without rotation.

Incubation time for conjugate dilution $1 \mathrm{hr}$ in a waterbath at $37^{\circ} \mathrm{C}$.

With these modifications it was possible to perform the whole procedure within one working day ( $5 \mathrm{hrs}$ ), because antigen coating of the tubes could be done the previous day. These modifications did not influence the sensitivity. All experiments were performed on semi-automated equipment for enzyme analysis (Olli system 3000: Olli, Kivenlahti, Finland).

\section{Results}

Table I shows the number of specimens detected by each test according to the clinical diagnosis. The

TABLE I Results of serological tests for syphilis on 'problem' sera, by clinical diagnosis

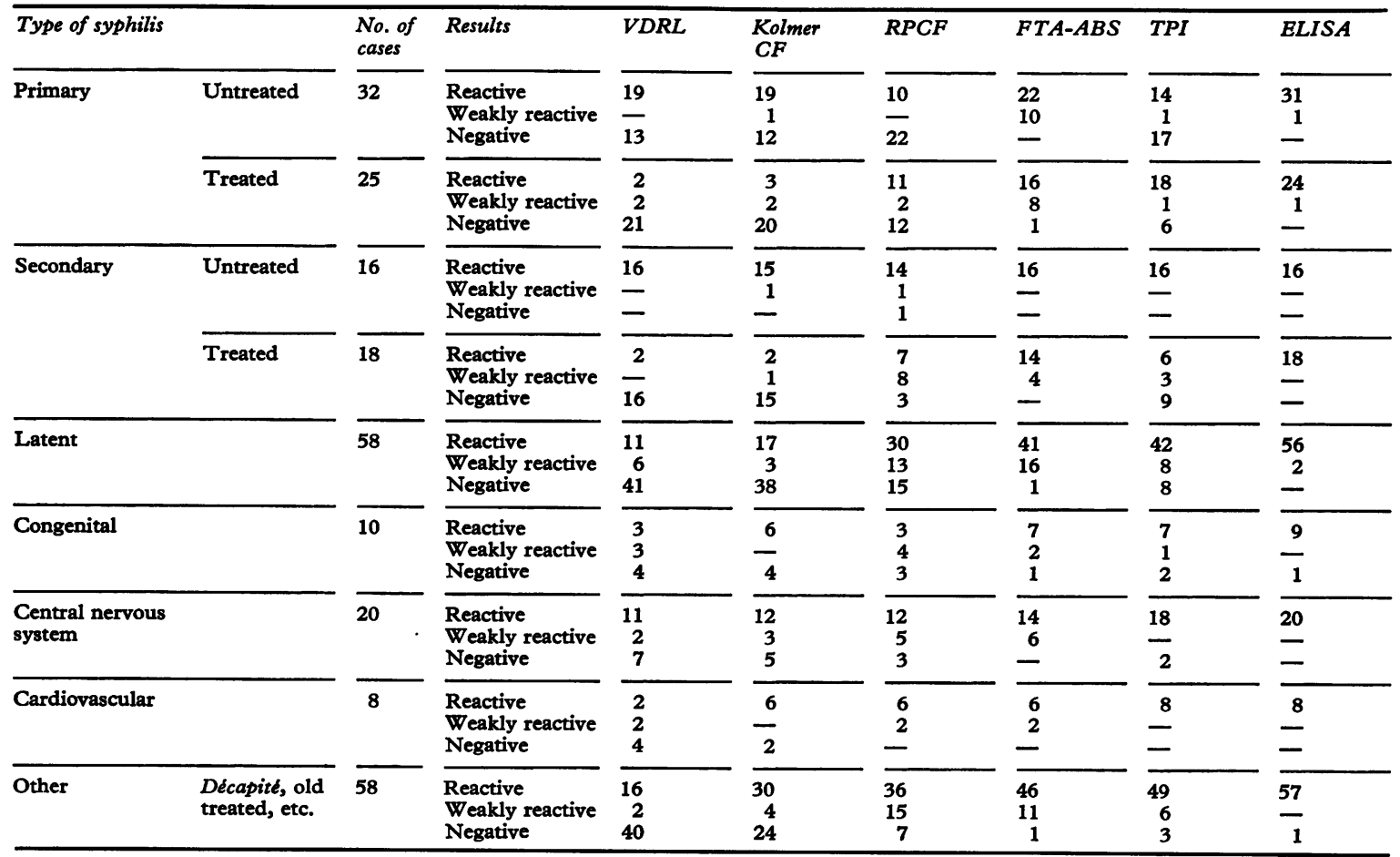


results in the VDRL, Kolmer CF, and RPCF tests were recorded as reactive when the titre was $1: 2$ or higher. A titre of $1: 1$ was recorded as weakly reactive. The result of the FTA-ABS test was considered as reactive when the score was ++ or more, and as weakly reactive when the score was + .

The result of the ELISA was given as reactive when the extinction value was equal to or higher than the weakly positive control serum and as weakly reactive when the value was a little below the weakly positive control serum (see material and methods).

The result of the TPI test was given as reactive when immobilization was more than 50 per cent., as weakly reactive when immobilization was $20-50$ per cent., and as negative when it was less than 20 per cent.

\section{Primary syphilis}

Tests were performed on 32 untreated cases and on 25 treated cases 2 months to 2 years after treatment.

In primary syphilis the sensitivity of the ELISA is equal to the FTA-ABS (100 per cent.), and with ELISA no cases of primary syphilis were missed (Table I).

\section{Secondary syphilis}

Tests were performed on sixteen untreated cases and on eighteen treated cases 2 months to 2 years after treatment. ELISA was positive in all cases in both groups, a sensitivity equal to the FTA-ABS. In the treated cases of secondary syphilis, the TPI was negative in nine instances (Table I).

\section{Latent syphilis}

Tests were performed on 58 cases (treated and untreated). The ELISA was reactive in 56 cases and gave weakly reactive (doubtful) results in two. The FTA-ABS was negative in one case and the TPI in eight. The results of the RPCF test were much better than those of the cardiolipin tests (Table I).

\section{Congenital syphilis}

Tests were performed on ten cases (treated and untreated). The ELISA was reactive in nine cases and negative in one, which was weakly reactive $(+)$ in the FTA-ABS. The FTA-ABS was reactive in seven cases, weakly reactive in two, and negative in one, which was reactive in the ELISA. The TPI test was reactive in eight cases and negative in 2 (Table I).

\section{Syphilis of the central nervous system}

Tests were performed on twenty cases (treated and untreated). The ELISA was reactive in all cases and the FTA-ABS was reactive in fourteen cases and weakly reactive in six. The TPI was reactive in eighteen cases and negative in two (Table I).

\section{Cardiovascular syphilis}

Tests were performed on eight cases (treated and untreated). The ELISA and TPI were reactive in all cases, and the FTA-ABS was reactive in six cases and weakly reactive in two (Table I).

\section{Other cases of syphilis}

Tests were performed on 58 other cases (treated and untreated). Most of these were old treated cases, but the stage at which treatment had been given was not known. Four patients were treated for gonorrhoea but it became evident from the serological tests that they also had early syphilis. We called these cases 'syphilis décapité. The ELISA was reactive in 57 cases and negative in one. The FTA-ABS was reactive in 46 cases, weakly reactive in eleven, and negative in one. The TPI was reactive in 55 cases and negative in three (Table I).

\section{Presumed biological false positive reactors (BFP)}

Tests were performed on 42 BFP reactors. The ELISA was negative in 41 cases, and weakly reactive in one, which had a positive RPCF test (1:4). FTAABS and TPI tests were negative in all 42 cases.

Sera of persons in whom the risk of syphilis infection was especially high

This group consisted of 220 persons who attended a Venereal Disease Clinic. There was no clinical evidence of syphilis and the VDRL, Kolmer, RPCF, FTA-ABS, and TPI tests were negative in all cases. In two cases the ELISA test was reactive and in one weakly reactive. One of the two reactive sera was from a patient with a Candida albicans balanitis and the other from a patient whose serum had given chronic anticomplementary reactions. The weakly reactive serum was from an immigrant from Surinam who had been treated there for an endemic treponematosis. On retesting, the serum giving chronic anticomplementary reactions became negative in the ELISA, but the other two remained reactive.

Sera of persons with only weakly positive FTA-ABS $(+)$ test with no clinical evidence or history of syphilis (BFP FTA-ABS ?)

The ELISA was reactive in five of these ten persons and negative in five.

\section{Reproducibility}

The reproducibility of the ELISA test was tested by comparing the results of triplicate tests on twenty syphilitic sera. No great differences were found in the extinction value and the results were always above the extinction value of the weakly positive control serum. 


\section{Discussion}

The results presented in this paper show that the ELISA specificity is high, although a definite conclusion in this respect is possible only when a larger number of sera has been screened with this method. The test was reactive in two cases and weakly reactive in one case among the 220 persons in whom the risk of syphilis infection was especially high, but whose sera were negative in the other tests. One of these was a patient with an endemic treponematosis.

In the group of patients with presumed biological false positive results in the VDRL, Kolmer, and RPCF tests (Table II), the ELISA was weakly reactive in one of 42 cases. This serum was also positive in the RPCF test $(1: 4)$ so that old syphilis cannot be ruled out. In the ten persons with a weakly reactive FTA-ABS test $(+)$, but without clinical evidence or a history of syphilis, the ELISA was reactive in 50 per cent. We are not sure whether these reactions are non-specific.

The investigations carried out on the group of 245 syphilitic sera showed that the sensitivity of the ELISA at all stages of syphilis is very high and equal to that of the FTA-ABS test (Tables II and III). In our group of syphilitic sera, the ELISA was positive in 99 per cent., the VDRL in 40 per cent., the Kolmer in 51 per cent., the RPCF in 75 per cent., the TPI in 81 per cent., and the FTA-ABS in 98 per cent. (Table III).

The results indicate that, because of its high specificity and high sensitivity, the ELISA test is of great diagnostic value and that the range of its application is wide.

Because alkaline phosphatase is available only in limited quantities, it is not possible to use it on a large scale. It is, however, also possible to use the enzyme peroxidase in the ELISA (van Weemen and Schuurs, 1971) and this is to be preferred for large scale application (Ruitenberg and others, 1974).

It is concluded that the qualities of the ELISA test, with the potential for mechanization of all steps, justify its application in the future as a first-line screening procedure for syphilis. In this respect a micro-test of ELISA, which only needs very small quantities of antigen, is now being developed in our Institute.

\section{Summary}

The enzyme-linked immunosorbent assay (ELISA) technique, using an ultrasonicate of Treponema pallidum as antigen, has been evaluated as a serological test for syphilis. It is concluded that the test is simple, reliable, and relatively quick and that its

TABLE II Results of serological tests for syphilis on sera of presumed biological false positive reactors

\begin{tabular}{|c|c|c|c|c|c|c|c|c|}
\hline Diagnosis & $\begin{array}{l}\text { No. of } \\
\text { cases }\end{array}$ & Results & VDRL & $\begin{array}{l}\text { Kolmer } \\
\text { CF }\end{array}$ & $R P C F$ & $F T A-A B S$ & $T P I$ & ELISA \\
\hline \multirow{3}{*}{$\begin{array}{l}\text { Presumed biological false } \\
\text { positive reaction }\end{array}$} & 42 & Reactive & 6 & 12 & 11 & - & - & - \\
\hline & & Weakly reactive & 8 & 6 & 5 & - & - & 1 \\
\hline & & Negative & 28 & 24 & 26 & 42 & 42 & 41 \\
\hline
\end{tabular}

TABLE III Reactive and weakly reactive results (per cent.) of serological tests for syphilis on 'problem' sera, by clinical diagnosis

\begin{tabular}{|c|c|c|c|c|c|c|c|c|}
\hline \multirow[b]{2}{*}{ Type of syphilis } & & \multirow[b]{2}{*}{ No. of cases } & \multicolumn{6}{|c|}{ Results (per cent.) } \\
\hline & & & $V D R L$ & Kolmer $C F$ & $R P C F$ & $F T A-A B S$ & $T P I$ & ELISA \\
\hline \multirow[t]{2}{*}{ Primary } & Untreated & 32 & 59 & 62 & 31 & 100 & 47 & 100 \\
\hline & Treated & 25 & 16 & 20 & 52 & 96 & 76 & 100 \\
\hline \multirow[t]{2}{*}{ Secondary } & Untreated & 16 & 100 & 100 & 94 & 100 & 100 & 100 \\
\hline & Treated & 18 & 11 & 17 & 83 & 100 & 50 & 100 \\
\hline Latent & & 58 & 29 & 34 & 74 & 98 & 86 & 100 \\
\hline Congenital & & 10 & 60 & 60 & 70 & 90 & 80 & 90 \\
\hline Central nervous system & & 20 & 65 & 75 & 85 & 100 & 90 & 100 \\
\hline Cardiovascular & & 8 & 50 & 75 & 100 & 100 & 100 & 100 \\
\hline Other & $\begin{array}{l}\text { Décapité, old treated } \\
\text { cases, etc. }\end{array}$ & 58 & 31 & 59 & 88 & 98 & 95 & 98 \\
\hline & Total & 245 & 40 & 51 & 75 & 98 & 81 & 99 \\
\hline
\end{tabular}


sensitivity in all stages of syphilis is equal to the FTAABS test. Because its specificity is probably also high, ELISA might be used in future as a first-line screening test for the serodiagnosis of syphilis.

The authors are grateful to Dr. A. M. Hagenaars, National Institute of Public Health, the Netherlands, for the preparation of the enzyme-linked conjugates, and to Dr. J. H. Bekker for critical reading of the manuscript. We should also like to thank Mr. P. A. Steerenberg and Mr. B. J. A. Brosi for their technical assistance.

\section{References}

D'Alessandro, G., and Dardanoni, L. (1953) Amer. $\mathcal{F}$. Syph., 37, 137

BekKeR, J. H., DE BRUIJN, J. H., and MilleR, J. N. (1966) Brit. F. vener. Dis., 42, 42 and OnvLeE, P. C. (1955) Antonie van Leeuwenhoek, 21, 331

Engvall, E., and PerlmanN, P. (1971) Immunochemistry, 8,871

(1972) F. Immunol., 109, 129

KeNT, J. F., and DE WeERDT., J. B. (1963) Brit. F. vener. Dis., 39, 37

Miller, J. N., De Bruijn, J. H., Bekker, J. H., and ONVLEE, P. C. (1966) f. Immunol., 96, 450

Ruitenberg, E. J., Ljungström, J., SteERenberg, P. A., and BuYs, J. (1975) Ann. N.Y. Acad. Sci. (in press)

United States Public Health Service (1969) 'Manual of Tests for Syphilis'. Venereal Disease Program, National Communicable Disease Center, Atlanta, Georgia

vaN WeEMEN, B. K., and SchuURS, A. H. W. M. (1971) F.E.B.S. Letters, 15, 232 